

\title{
Evidence of physical violence and torture in refugees and migrants seeking asylum in France
}

Patrícia Duarte Deps, Simon M. Collin, Hugo Pessotti Aborghetti, Philippe

Charlier

\section{- To cite this version:}

Patrícia Duarte Deps, Simon M. Collin, Hugo Pessotti Aborghetti, Philippe Charlier. Evidence of physical violence and torture in refugees and migrants seeking asylum in France. Journal of Forensic and Legal Medicine, 2021, 77, 10.1016/j.jflm.2020.102104 . hal-03141044

\author{
HAL Id: hal-03141044 \\ https://hal.science/hal-03141044
}

Submitted on 15 Feb 2021

HAL is a multi-disciplinary open access archive for the deposit and dissemination of scientific research documents, whether they are published or not. The documents may come from teaching and research institutions in France or abroad, or from public or private research centers.
L'archive ouverte pluridisciplinaire HAL, est destinée au dépôt et à la diffusion de documents scientifiques de niveau recherche, publiés ou non, émanant des établissements d'enseignement et de recherche français ou étrangers, des laboratoires publics ou privés. 


\section{Evidence of physical violence and torture in refugees and migrants seeking asylum in France}

Patrícia Deps, ${ }^{1,2,3 *}$ Simon M Collin, ${ }^{4}$ Hugo Pessotti Aborghetti, ${ }^{1}$ Philippe Charlier ${ }^{3}$

${ }^{1}$ Department of Social Medicine, Federal University of Espírito Santo, Vitória, Espírito Santo, Brazil

${ }^{2}$ Centre d'Accueil et de Soins Hospitaliers (CASH) \& Institut de la Précarité et de l'Exclusion Sociale (IPES), avenue de la République, 92000 Nanterre, France

${ }^{3}$ Paris-Saclay University (UVSQ), Laboratory of Anthropology, Archaeology \& Biology (LAAB), 2 avenue de la Source de la Bièvre, 78180 Montigny-Le-Bretonneux,France

${ }^{4}$ Public Health England, London, United Kingdom

* Corresponding author: Professor Patrícia Deps, Department of Social Medicine, Universidade Federal do Espírito Santo, Av. Marechal Campos 1468, Maruípe, Vitória-ES, Brazil; patricia.deps@ufes.br

Running head: Evidence of physical violence and torture in asylum-seekers in France

Declarations of interest: none

Funding: this study received no specific funding 


\section{ABSTRACT}

Objectives: The increasing numbers of migrants and refugees to Europe include persons seeking asylum, many of whom will have experienced physical violence and torture. Here we describe the personal histories and clinical evidence of violence and torture among attendees at a public health specialist service in France.

Methods: Physicians in a multidisciplinary team conducted examinations to corroborate refugees' skin lesions and other signs of injury with self-reported histories of physical violence and torture to provide evidence for asylum applications.

Results: The 240 asylum seekers assessed between 10/2016 and 09/2018 were mostly male $(89 \%(213 / 240))$ with median age 29 years (IQR 26-34 years) and originating from north and west Africa. Consultations took place on average 15 months after arrival in France. In most cases $(58 \%)$ the reason for seeking asylum was political persecution. Almost all attendees (94\%) presented with scars. The most common mechanisms of injury were beatings ( $84 \%)$, burns $(32 \%)$ and cuts/stab wounds (15\%). Sexual violence was reported for 37\% of women $(10 / 27)$ and $4 \%$ of men (9/213). Police tended to use multiple methods for inflicting injuries, whereas the army and non-state actors mostly inflicted beatings. Sexual violation was most commonly reported for violence inflicted by family members or partners. Corroboration of lesions with patients' histories of physical violence and torture was affirmative in $93 \%$ $(224 / 240)$ of cases.

Conclusion: This ethnically diverse group presented with evidence of physical violence and torture, demonstrating the importance of providing a specialist service for asylum seekers including expertise in forensic dermatology and medical anthropology.

Key words: refugees; asylum seekers; Europe; torture; violence 


\section{INTRODUCTION}

In European countries the number of applications for asylum increased dramatically with the large influx of migrants and refugees into the region in 2015-2016. ${ }^{1}$ This placed high demand on health care teams and physicians, who need to recognize and certify cases of physical abuse and torture as supporting evidence for asylum applications. The Istanbul Protocol, a guideline created by the United Nations (UN) for health care professionals assisting victims of torture, gives guidance about examination and evaluation related to specific forms of torture, such as beating and other types of blunt trauma, burns, dental damage, and sexual violation. $^{2}$

A 'medical anthropology' outpatient and outreach service was created within the Department of Public Health at Nanterre Hospital, Paris, in 2015, to provide multidisciplinary general medical and psychiatric health care for the most deprived and vulnerable population groups, including assistance with finding shelter for homeless people, medical care for inmates of the Hauts-de-Seine prison, and health care for refugees and migrants. ${ }^{3}$ The latter group includes those for whom the purpose of the consultation is for physicians to recognize signs of physical violence and torture, to corroborate self-reported histories and to provide clinical evidence in support of applications for asylum.

This study describes patient histories and the skin lesions and other injuries arising from physical violence and torture in asylum seekers attending the service between October 2016 and September 2018. Our aim was to characterize this specific group as representative of the types of case encountered by physicians practicing in European and other refugee-receiving countries in recent years and probably for the foreseeable future. 


\section{METHODS}

\section{Study setting}

The outpatient service provides multidisciplinary general medical and psychiatric health care for deprived and vulnerable population groups, including refugees seeking asylum. The rationale for the medical anthropological aspect of the service is to manage the social and cultural complexity of cases, including differential diagnosis of lesions caused by ethnic practices, and to provide patient-centered care that is sensitive to the patient's identity, sociocultural background and life story. The service does not constitute a Medico-Judicial Unit (Unité Médico-Judiciaire) as defined by the Ministère de la Justice in that none of the patients are French citizens and no legal complaint or judicial procedure is pending, but provision of care provided an implicit recognition of refugee status. ${ }^{4}$

\section{Medical consultations and data collection}

The service provides weekly consultations lasting 30-120 minutes, depending on the complexity of the case and the need for translation. The purpose of consultation is to obtain an objective injury assessment in terms of physical violence inflicted on the patient, including torture and mutilation, but with sensitivity towards the social and cultural context of the patient's place of origin. All patients receive a general medical assessment and an external examination to identify lesions. Assessments can lead to referral for radiographic (X-ray) and computed tomography (CT) scans to confirm skeletal lesions and to locate foreign bodies such as bullets and shrapnel. Referrals can also be made for patients to receive specialist psychological support. The medical outcome of the consultation is a report which is provided to the patient for use in support of their application for asylum. Data for this study were extracted from routinely-collected forms and notes completed during the consultation. 


\section{Ethical approval}

All consultations followed the Istanbul Protocol for the Effective Investigation and

Documentation of Torture and Other Cruel, Inhuman or Degrading Treatment or

Punishment. ${ }^{2}$ This study was based on anonymized data collected routinely by the service and did not require ethical review.

\section{RESULTS}

Data were available for 240 asylum seekers who attended the service between October 2016 and September 2018. Two-thirds were from 5 countries in north and west Africa: $29 \%$ (69) from Sudan, 15\% (36) Guinea Conakry, 8\% (19) Morocco, 8\% Ivory Coast, 6\% (15) Western Sahara, and 5\% (12) Somalia (Figure 1, Supplementary File Table S1). Over one-third of all asylum seekers $(38 \%(92 / 240))$ reported travelling via Libya to Italy, 5\% (12/240) via or from Morocco to Spain (Supplementary File Figure S1).

The asylum seekers were mostly male (89\% (213/240)) with median age 29 years (IQR 26-34 years) (Supplementary File Figure S2). Male asylum seekers were slightly younger (median 28 years) than female asylum seekers (median 32 years). Ethnicity was reported for $68 \%$ $(164 / 240)$ of the asylum seekers, with around 100 different ethnic groups represented.

Consultations took place on average 15 months after arrival in France (median 13, IQR 8-18 months) and 6 years (median 4, IQR 2-8 years) since problems had begun for the individual in the country of origin. In most cases (58\%) the problem was political persecution and physical violence was perpetrated by state actors (police or military) (Table 1). Countries in which violence by non-state actors occurred included Afghanistan (5/5), Somalia (4/12) and Sudan (14/69) (Figure 2). 
Almost all attendees (94\%) presented with scars. The most common mechanisms of injury were beatings (84\%), burns (32\%) and cuts/stab wounds $(15 \%) ; 8 \%(19 / 240)$ had experienced sexual violence (Table 2). Sexual violence was reported for $37 \%$ of women $(10 / 27)$ and $4 \%$ of men $(9 / 213)$. Countries in which burns were commonly inflicted included Guinea Conakry (12/36), Ivory Coast (5/19), Morocco (8/19), and Sudan (29/69) (Figure 2,

\section{Supplementary File Figure S4).}

Lesions occurred most commonly on legs $(56 \%(135 / 240))$, arms $(50 \%(120 / 240))$, the face $(42 \%(101 / 240))$, and trunk $(30 \%(71 / 240))$, followed by scalp $(21 \%(50 / 240))$, hands $(20 \%$ (48/240) and feet (16\% (39/240)) (Supplementary File Table S2).

Police tended to use multiple methods for inflicting torture and injury, with 78 cases reporting 134 types of violence (Supplementary File Table S3), whereas the army and nonstate actors mostly inflicted beatings. Sexual violation was most commonly reported for violence inflicted by family members or partners.

Skin lesions relating to ethnic practices were recorded for 14\% (34/240) of asylum seekers, representing $7 \%(2 / 27)$ of women and $15 \%(32 / 213)$ of men. Two-thirds $(68 \%(23 / 34))$ of asylum seekers with ethnic scars were from Sudan, with 4 from Chad, 2 each from Niger and Somalia, and one each from Bangladesh, Ethiopia and Togo. Of the 225 attendees presenting with scars, $15 \%(34 / 225)$ had a skin lesion related to an ethnic practice. The main causes of ethnic lesions were healing practices $18 \%$ (6/34) and magico-religious rituals $21 \%(7 / 34)$.

Clinical corroboration of lesions with patients' histories of physical violence and torture was affirmative in 93\% (224/240) of cases (including 31/34 cases with ethnic lesions), negative in $4 \%(9 / 240)$, undecided in 2 cases, and not recorded in 5 cases (including $3 / 34$ cases with ethnic lesions). 


\section{DISCUSSION}

This group of asylum seekers accessing a specialist outpatient service in France, although geographically and ethnically diverse nonetheless presented with certain commonalities, including the reasons for leaving their country of origin (mostly due to political persecution), the perpetrators of violence against them (mostly state actors), presenting with physical scars, and having been beaten. Personal accounts of torture and violence were corroborated by medical examination in almost all cases.

The most commonly-reported forms of torture result in skin lesions, including those caused by abrasions, contusions, lacerations, puncture wounds, and burns from cigarettes, heated instruments or electric shocks, ${ }^{5}$ but skin lesions can also be caused by ethnic practices as we observed in more than 1 in 10 of our cases. Multiple causes of lesions can also occur, with the 240 asylum seekers in our group reporting 370 different mechanisms of injury plus scars from ethnic practices. These aspects underscore the importance of incorporating expertise in forensic dermatology and medical anthropology into a medical service for this patient group. ${ }^{3,6}$ Knowledge of physical and social anthropology and cultural practices in countries of origin is crucial in considering differential diagnoses of traumatic lesions, to establish whether patients' histories corroborate with physical signs in cases where ritual scarifications and scars from injuries can have a similar appearance or where injuries may be not have arisen from torture..$^{5,7,8}$

A strength of our study is that the service where the data were collected benefited from both types of expertise, dermatological and anthropological, among the physicians providing assessment and care. The main limitations of our study are the reliability of patients' recall of information and missing data. The patients using our service were mainly from North and sub-Saharan Africa - asylum applicants from Albania, Afghanistan and Haïti were not 
represented, despite these being the top three countries of origin for asylum applicants in France during the period of the study, followed by Sudan, Guinea, Syria, Ivory Coast, and DR Congo. ${ }^{9}$ This difference probably reflects the migrant population in the area of Paris where the service is located. The clinical generalizability of our findings is supported by a recent review of skin lesions and differential diagnoses in potential survivors of torture and by guidelines for medical examination of victims of torture, both of which describe the types of lesions that we found in our group. ${ }^{5}$

Our group included a smaller proportion of women than has been reported overall for asylum seekers in France. ${ }^{10,11}$ Again, these differences presumably relate to the catchment area for our service. Despite the relatively small numbers of women, our data showed that female asylum seekers commonly reported sexual violence as a reason for leaving their country of origin, which highlights the importance of providing specialist care for women seeking asylum. $^{12-14}$

Our study has described the physical effects of torture and physical violence in asylum seekers attending the service. Clearly, the physical violence which gave rise to visible lesions and other traumatic experiences before, during and after the asylum seekers journey to France will have an impact on mental health. ${ }^{15-17}$ Our service includes the provision of psychological support to asylum seekers through specialist consultations at the service and an additional monitoring network with visits to places of temporary accommodation whilst asylum seekers await decisions about their applications.

Ideally, a medical service for asylum seekers would also be able to provide or signpost service users to broader forms of care and support, including assistance in meeting basic needs such as food, accommodation and legal advice. ${ }^{18-20}$ Unfortunately, the situation for asylum seekers in France reflects a political trend towards tightening rules around asylum, 
such as (in 2018) shortening asylum application deadlines, removing the suspensive effect of appeals, and increasing the detention time before deportation following a failed application, and (in 2019) introducing a 3-month wait before asylum seekers qualify for non-urgent health care. ${ }^{21}$ In this increasingly hostile environment, provision of dedicated multidisciplinary services staffed by professionals with combined expertise in the medical, cultural, psychological, social, and legal aspects of the asylum process. 


\section{REFERENCES}

1. Asylum Information Database (AIDA). European Council on Refugees and Exiles (ECRE); 2019 [cited 2019 11/02/2020]. Available from: http://www.asylumineurope.org/.

2. UN Office of the High Commissioner for Human Rights. Manual on the Effective Investigation and Documentation of Torture and Other Cruel, Inhuman or Degrading Treatment or Punishment ("Istanbul Protocol"). Geneva: United Nations, 2004.

3. Charlier P. [Medical anthropology consultations for refugees: Why are they necessary?]. Ann Dermatol Venereol. 2017 Feb;144(2):89-91. PubMed PMID: 27989391. Epub 2016/12/19. Une consultation d'anthropologie medicale ouverte aux migrants : pour quoi faire? fre.

4. Circulaire du 25 avril 2012 relative à la mise en œuvre de la réforme de la médecine légale, (2012).

5. Clarysse K, Grosber M, Ring J, Gutermuth J, Kivlahan C. Skin lesions, differential diagnosis and practical approach to potential survivors of torture. J Eur Acad Dermatol Venereol. 2019 Jul;33(7):1232-40. PubMed PMID: 30659672. Epub 2019/01/20. eng.

6. Charlier P, Dagenais-Everell C. Two regards on forensic expertises: Crisis of migrants and autopsies. Ethics, Medicine and Public Health. 2016 2016/01/01/;2(1):156-8.

7. Charlier P, Bou Abdallah F, Mostefai Dulac Y, Deo S, Jacqueline S, Brun L, et al. ["Palimpsest scar" lesions in a context of torture (Darfur, Sudan)]. Ann Dermatol Venereol. 2017 Nov;144(11):696-9. PubMed PMID: 28728860. Epub 2017/07/22. Cicatrices $<<$ palimpsestes $>>$ en contexte de torture (Darfour, Soudan). fre.

8. Charlier P, Haroun A, Herve C. Deliberate chemical dermatoglyphic burns in a political refugee. Ann Dermatol Venereol. 2017 Feb;144(2):130-1. PubMed PMID: 27988145. Epub 2016/12/19. eng.

9. Forum réfugiés-Cosi. Country Report: France 2017 [11/02/2020]. Available from: https://www.forumrefugies.org/.

10. Freedman J. Gendering the International Asylum and Refugee Debate. London: Palgrave Macmillan UK; 2007.

11. Clement R, Lebosse D, Barrios L, Rodat O. Asylum seekers alleging torture in their countries: Evaluation of a French center. J Forensic Leg Med. 2017 Feb;46:24-9. PubMed PMID: 28064088. Epub 2017/01/09. eng.

12. Freedman J. Sexual and gender-based violence against refugee women: a hidden aspect of the refugee "crisis". Reproductive health matters. 2016 May;24(47):18-26. PubMed PMID: 27578335. Epub 2016/09/01. eng.

13. Tantet $\mathrm{C}$, Delaporte C, Cordel H. [Violence against migrant and refugee women: how to identify them]. Rev Prat. 2019 Jun;69(6):676-8. PubMed PMID: 31626433. Epub 2019/10/19. Violences faites aux femmes migrantes : mieux les reperer. fre.

14. Charlier P, Bou Abdallah F, Brun L, Hoang-Oppermann V, Deo S, Mostefai-Dulac Y, et al. [The myth of virgin cleansing: Latest news on an archaic magico-religious practice].

Ann Dermatol Venereol. 2018 Mar;145(3):178-81. PubMed PMID: 29221651. Epub 2017/12/10. Le mythe du nettoyage par les vierges : actualite d'un archaisme magicoreligieux. fre. 
15. Abbott A. The mental-health crisis among migrants. Nature. 2016 Oct 13;538(7624):158-60. PubMed PMID: 27734887. Epub 2016/10/14. eng.

16. Grupp F, Moro MR, Nater UM, Skandrani SM, Mewes R. "It's That Route That Makes Us Sick": Exploring Lay Beliefs About Causes of Post-traumatic Stress Disorder Among Sub-saharan African Asylum Seekers in Germany. Front Psychiatry. 2018;9:628. PubMed PMID: 30534091. Pubmed Central PMCID: PMC6275318. Epub 2018/12/12. eng.

17. Charlier P, Duverger P, Abdallah FB. Memory recall of traumatic events in refugees. Lancet. 2018 Nov 17;392(10160):2170. PubMed PMID: 30496100. Epub 2018/11/30. eng.

18. Gosselin A, Desgrees du Lou A, Lelievre E, Lert F, Dray-Spira R, Lydie N, et al. Understanding Settlement Pathways of African Immigrants in France Through a Capability Approach: Do Pre-migratory Characteristics Matter? Eur J Popul. 2018 Dec;34(5):849-71. PubMed PMID: 30976264. Pubmed Central PMCID: PMC6261851. Epub 2018/01/22. eng.

19. Lefebvre O, Maille D. [Access to rights, access to care: what obstacles for migrants ?]. Rev Prat. 2019 May;69(5):567-74. PubMed PMID: 31626470. Epub 2019/10/19. Acces aux droits, acces aux soins : quels obstacles pour les migrants? fre.

20. Martin-Fernandez J, Lioret S, Vuillermoz C, Chauvin P, Vandentorren S. Food Insecurity in Homeless Families in the Paris Region (France): Results from the ENFAMS Survey. Int J Environ Res Public Health. 2018 Feb 28;15(3). PubMed PMID: 29495563. Pubmed Central PMCID: PMC5876965. Epub 2018/03/03. eng.

21. Human Rights Watch. 2019 [cited 2019 11/02/2020]. Available from: https://www.hrw.org/world-report/2019/country-chapters/france. 


\section{FIGURE LEGENDS}

Figure 1. Countries of origin of asylum seekers attending the specialist outpatient service in Nanterre, France, during the period 10/2016-09/2018

Figure 2. Perpetrators of violence (by country of origin) against asylum seekers attending the specialist outpatient service in Nanterre, France, during the period 10/2016-09/2018 
Table 1. Reasons for leaving country of origin and perpetrators of violence against asylum seekers attending the specialist outpatient service in Nanterre, France, during the period 10/2016-09/2018

\begin{tabular}{|lrr|}
\hline Reason for seeking asylum ${ }^{\dagger}$ & $\mathbf{n}$ & $\mathbf{\%}$ \\
Political persecution & 140 & 58.3 \\
Family dispute & 22 & 9.2 \\
Tribal/inter-ethnic conflict & 13 & 5.4 \\
Religious persecution & 9 & 3.8 \\
Other & 23 & 9.6 \\
Not stated & 44 & 18.3 \\
& & \\
Perpetrators & & \\
Police & 78 & 32.5 \\
Army & 21 & 8.8 \\
Non-state actors & 30 & 12.5 \\
Family or partner & 21 & 8.8 \\
Other & 18 & 7.5 \\
\hline
\end{tabular}

$\dagger$ Total (251) exceeds size of group because some asylum seekers reported more than one reason

$\$$ Reported by 160 asylum seekers; total exceeds this because some asylum seekers reported more than one type of perpetrator 
Table 2. Principal lesions and self-reported mechanisms of injury among asylum seekers attending the specialist outpatient service in Nanterre, France, during the period 10/2016-09/2018

\begin{tabular}{|c|c|c|}
\hline Lesions and injuries ${ }^{\dagger}$ & $\mathbf{n}$ & $\%$ \\
\hline Scar & 225 & 93.8 \\
\hline Dental & 57 & 23.8 \\
\hline Trauma & 24 & 10.0 \\
\hline Deformity/dislocation & 10 & 4.2 \\
\hline Ophthalmic & & 2.9 \\
\hline Mechanisms of injury & n & $\%$ \\
\hline Beaten & 201 & 83.8 \\
\hline Burned & 76 & 31.7 \\
\hline Cut/stabbed & 35 & 14.6 \\
\hline Sexual violation & 19 & 7.9 \\
\hline Shot & 11 & 4.6 \\
\hline Hanging & 7 & 2.9 \\
\hline Nails removed & 6 & 2.5 \\
\hline Teeth removed & 5 & 2.1 \\
\hline Dragged & 5 & 2.1 \\
\hline Electrocuted & 5 & 2.1 \\
\hline
\end{tabular}

${ }^{\dagger} \mathrm{n}=26$ patients $(10.8 \%)$ presented with alopecia

$\$$ Other forms of torture and maltreatment reported included: food/water deprivation, $\mathrm{n}=11$ (4.6\%); sleep deprivation, $\mathrm{n}=3$ $(1.3 \%)$ 
Figure 1



Figure 2




Table S1 Countries of origin of asylum seekers attending the medical anthropology service in Nanterre during the period 2016-2018

\begin{tabular}{|c|c|c|}
\hline Country of origin ${ }^{\dagger}$ & $\mathbf{n}$ & $\%$ \\
\hline Sudan & 69 & 28.8 \\
\hline Guinea Conakry & 36 & 15.0 \\
\hline Ivory Coast & 19 & 7.9 \\
\hline Morocco & 19 & 7.9 \\
\hline Western Sahara & 15 & 6.3 \\
\hline Somalia & 12 & 5.0 \\
\hline Democratic Republic of Congo & 10 & 4.2 \\
\hline Bangladesh & 6 & 2.5 \\
\hline Ethiopia & 6 & 2.5 \\
\hline Niger & 6 & 2.5 \\
\hline Afghanistan & 5 & 2.1 \\
\hline Chad & 5 & 2.1 \\
\hline Algeria & 3 & 1.3 \\
\hline Congo-Brazzaville & 3 & 1.3 \\
\hline Libya & 3 & 1.3 \\
\hline Nigeria & 3 & 1.3 \\
\hline Syria & 3 & 1.3 \\
\hline Eritrea & 2 & 0.8 \\
\hline Mali & 2 & 0.8 \\
\hline Senegal & 2 & 0.8 \\
\hline
\end{tabular}

$\dagger$ There was one patient each from Angola, Cameroon, Colombia, Gabon, India, Iraq, Kuwait, Pakistan, Sri Lanka, Tibet, and Togo 
Table S2 Locations of lesions on body

\begin{tabular}{|lrr|}
\hline Scalp & n & \% \\
Face & 50 & 20.8 \\
Neck & 101 & 42.1 \\
Trunk & 18 & 7.5 \\
Abdomen & 71 & 29.6 \\
Back & 22 & 9.2 \\
Buttocks & 20 & 8.3 \\
Genitals & 16 & 6.7 \\
Hand & 4 & 1.7 \\
Wrist & 48 & 20.0 \\
Arm & 17 & 7.1 \\
Leg & 120 & 50.0 \\
Foot & 135 & 56.3 \\
\hline
\end{tabular}


Table S3 Mechanisms of injury by type of perpetrator

\begin{tabular}{|c|c|c|c|c|c|c|c|c|c|c|c|}
\hline Perpetrators & Cases & Beaten & Burned & $\begin{array}{c}\text { Cut or } \\
\text { stabbed }\end{array}$ & $\begin{array}{c}\text { Sexual } \\
\text { violation }\end{array}$ & Shot & Hanging & $\begin{array}{c}\text { Nails } \\
\text { removed }\end{array}$ & $\begin{array}{c}\text { Teeth } \\
\text { removed }\end{array}$ & Dragged & $\begin{array}{c}\text { Electric } \\
\text { shock }\end{array}$ \\
\hline Police & 78 & $73(94 \%)$ & $30(38 \%)$ & $13(17 \%)$ & $3(4 \%)$ & $3(4 \%)$ & $4(5 \%)$ & $2(3 \%)$ & $2(3 \%)$ & $1(1 \%)$ & $3(4 \%)$ \\
\hline Army & 21 & $15(71 \%)$ & $5(24 \%)$ & $2(10 \%)$ & $2(10 \%)$ & $0(0 \%)$ & $1(5 \%)$ & $0(0 \%)$ & $0(0 \%)$ & $2(10 \%)$ & $0(0 \%)$ \\
\hline Non-state actors & 30 & $26(87 \%)$ & $8(27 \%)$ & $5(17 \%)$ & $0(0 \%)$ & $2(7 \%)$ & $0(0 \%)$ & $3(10 \%)$ & $0(0 \%)$ & $1(3 \%)$ & $0(0 \%)$ \\
\hline Family or partner & 21 & $20(95 \%)$ & $5(24 \%)$ & $1(5 \%)$ & $7(33 \%)$ & $0(0 \%)$ & $0(0 \%)$ & $0(0 \%)$ & $0(0 \%)$ & $0(0 \%)$ & $0(0 \%)$ \\
\hline Other & 18 & $9(50 \%)$ & $1(6 \%)$ & $3(17 \%)$ & $2(11 \%)$ & $1(6 \%)$ & $1(6 \%)$ & $0(0 \%)$ & $0(0 \%)$ & $0(0 \%)$ & $0(0 \%)$ \\
\hline
\end{tabular}


Figure S1. Routes taken to reach France (reported by 58/240 asylum seekers)

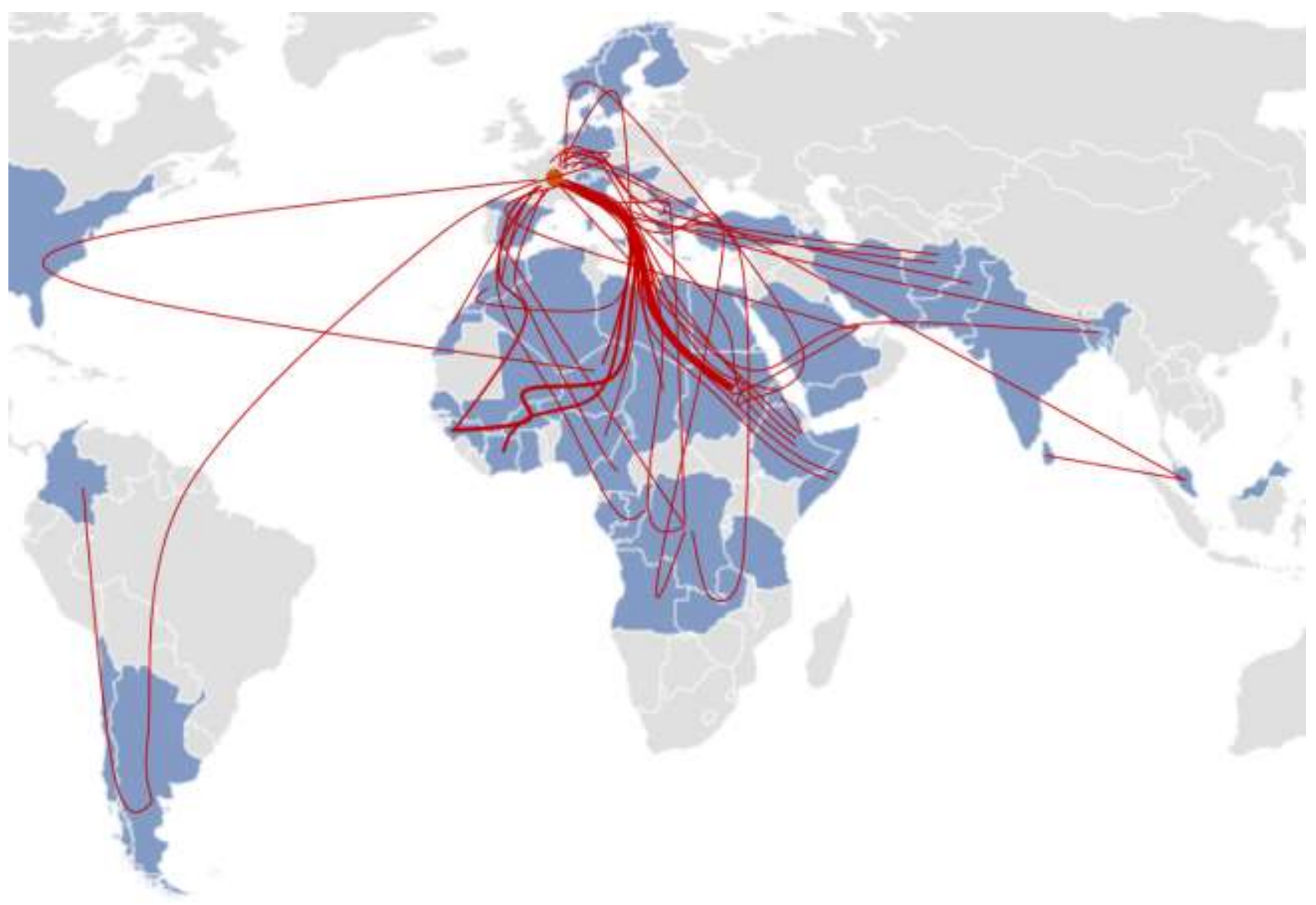

Figure S2. Age and sex of asylum seekers attending the medical anthropology service in Nanterre, France, during the period 2016-2018*




Figure S3. Reason for leaving country of origin and seeking asylum (by country of origin)

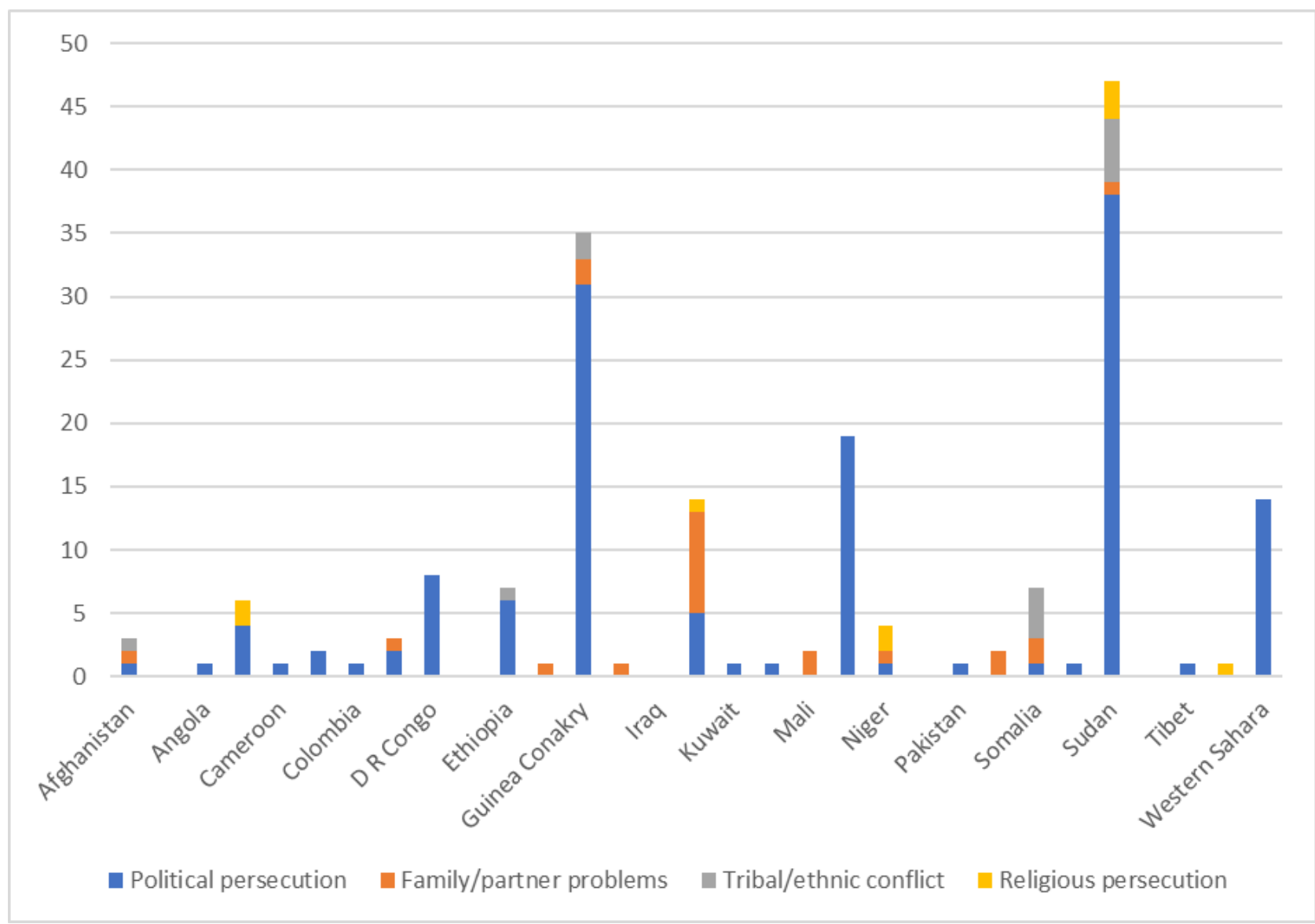

Figure S4. Mechanisms of injury (by country of origin)

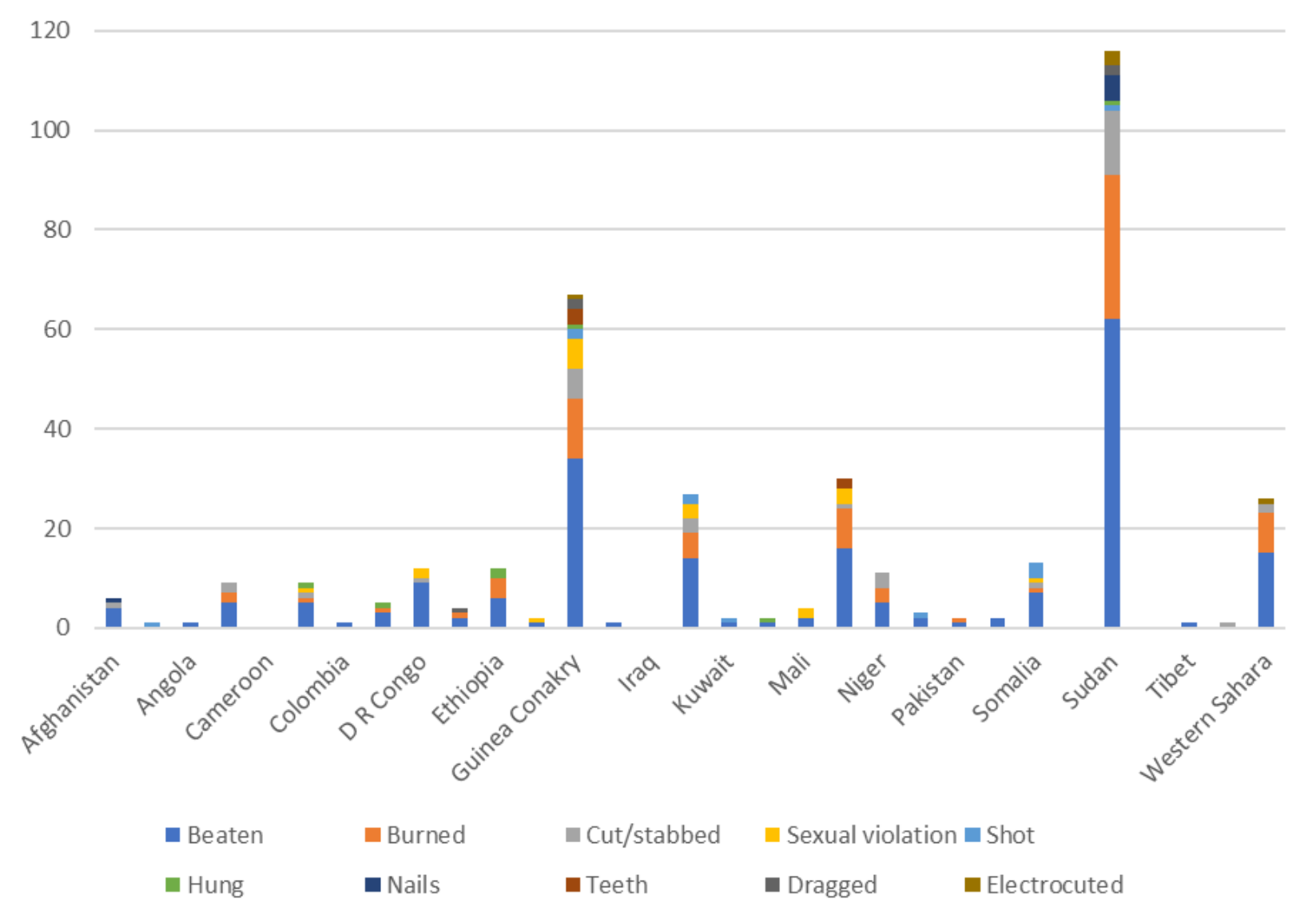

